\title{
Triple Collocation Evaluation of In Situ Soil Moisture Observations from $1200+$ Stations as part of the U.S. National Soil Moisture Network
}

\author{
Trent W. Ford, ${ }^{\mathrm{a}}$ Steven M. Quiring, ${ }^{\mathrm{b}}$ Chen Zhao, ${ }^{\mathrm{b}}$ Zachary T. Leasor, ${ }^{\mathrm{b}}$ And Christian Landry ${ }^{\mathrm{c}}$ \\ a Illinois State Climatologist Office, Climate and Atmospheric Science Section, Division of State Water Survey, Prairie Research \\ Institute, University of Illinois at Urbana-Champaign, Champaign, Illinois; ${ }^{\mathrm{b}}$ Atmospheric Sciences Program, Department of \\ Geography, The Ohio State University, Columbus, Ohio; ${ }^{\mathrm{c}}$ School of Earth Systems and Sustainability, Southern Illinois \\ University at Carbondale, Carbondale, Illinois
}

(Manuscript received 28 April 2020, in final form 20 July 2020)

\begin{abstract}
Soil moisture is an important variable for numerous scientific disciplines, and therefore provision of accurate and timely soil moisture information is critical. Recent initiatives, such as the National Soil Moisture Network effort, have increased the spatial coverage and quality of soil moisture monitoring infrastructure across the contiguous United States. As a result, the foundation has been laid for a high-resolution, real-time gridded soil moisture product that leverages data from in situ networks, satellite platforms, and land surface models. An important precursor to this development is a comprehensive, national-scale assessment of in situ soil moisture data fidelity. Additionally, evaluation of the United States's current in situ soil moisture monitoring infrastructure can provide a means toward more informed satellite and model calibration and validation. This study employs a triple collocation approach to evaluate the fidelity of in situ soil moisture observations from over 1200 stations across the contiguous United States. The primary goal of the study is to determine the monitoring stations that are best suited for 1) inclusion in national-scale soil moisture datasets, 2) deriving in situ-informed gridded soil moisture products, and 3) validating and benchmarking satellite and model soil moisture data. We find that $90 \%$ of the 1233 stations evaluated exhibit high spatial consistency with satellite remote sensing and land surface model soil moisture datasets. In situ error did not significantly vary by climate, soil type, or sensor technology, but instead was a function of station-specific properties such as land cover and station siting.
\end{abstract}

KEYWORDS: Soil moisture; Data quality control; Error analysis

\section{Introduction}

Soil moisture is a critical variable, impacting and informing a wide variety of scientific disciplines and applications. Soil moisture influences the climate system through modification of energy and moisture fluxes into the boundary layer, thereby influencing temperature, humidity, and precipitation (McPherson 2007; Seneviratne et al. 2010; Santanello et al. 2011). This influence, or memory, from anomalously wet or dry soils can have a persistent impact on the atmosphere, influencing the climate on monthly to seasonal time scales (Dirmeyer et al. 2009; Lorenz et al. 2010; Orth and Seneviratne 2014). Therefore, accurate soil moisture information is critical for subseasonal-to-seasonal climate prediction as well as forecasting extreme events at those time scales (Mahanama et al. 2008; Guo et al. 2011; Ford et al. 2018).

In addition to playing an integral role in the global climate system, soil moisture is often used as an indicator of agricultural drought (Quiring and Papakryiakou 2003). Recent studies have determined soil moisture as a key indicator of, and possible early warning for, flash drought in the United States (Ford et al. 2015; Ford and Labosier 2017; Otkin et al. 2018). Other important uses of soil moisture include for agricultural monitoring and decision-making (Phillips et al. 2014; Champagne et al. 2015; Soulis et al. 2015), weather prediction (Scipal et al. 2008; de Rosnay et al. 2014), streamflow and flood forecasting (Brocca et al. 2012; Wanders et al. 2014; Silvestro

Corresponding author: Trent W. Ford, twford@illinois.edu and Rebora 2014), soil and water quality monitoring (Quinn et al. 2010; Lloyd et al. 2016), military exercises (Flores et al. 2014), and storm power outage prediction (Quiring et al. 2011; Nateghi et al. 2014). The value of high-quality, timely soil moisture information is undeniable, echoed by the World Meteorological Organization deeming soil moisture as an essential climate variable (https://gcos.wmo.int/en/essentialclimate-variables/soil-moisture).

Because of its importance for countless, diverse applications, many operational and experimental soil moisture datasets have been made available over the last two decades. The majority of these products are based on modelsimulated soil moisture. For example, the University of Washington Experimental Surface Water Monitor (Wood 2008), the NOAA Climate Prediction Center soil moisture model (Fan and van den Dool 2004), the North American Land Data Assimilation System Phase 2 (NLDAS-2; Xia et al. 2012), and the Princeton Drought Monitoring and Forecasting project (Sheffield et al. 2014) all provide model-simulated soil moisture to support many applications. However, there are limitations to using model-derived soil moisture since each model has biases, and model performance varies significantly from region to region and model to model (Xia et al. 2015; Crow et al. 2018). Soil moisture monitoring from satellite remote sensing has advanced significantly over the last two decades to help address the observation needs left by modeling. The advantages of satellite remote sensing soil moisture include 1) actual observations of a quantity directly related to soil moisture, 2) spatial representativeness, and 3) relatively 
high temporal resolution that is sufficient for applications that require daily to weekly information. There are also limitations with remote sensing products including the inability to measure root zone soil moisture, spatiotemporal discontinuities in coverage, and limited historical data. Consequently, many operational and experimental soil moisture information systems leverage the strengths of satellite remote sensing and land surface modeling to produce soil moisture for many applications.

Likewise, in situ soil moisture observations are vital for a comprehensive soil moisture monitoring infrastructure. Direct, in situ observations provide the most accurate depiction of soil moisture conditions at the point of measurement, which is why they are frequently used to validate or benchmark model and satellite remote sensing soil moisture datasets (Crow et al. 2012; Sanchez et al. 2012; Chen et al. 2017; Xia et al. 2014; Ford and Quiring 2019). Previous studies have demonstrated that the inclusion of in situ observations improves the overall quality and usefulness of soil moisture information for multiple applications (Koster et al. 2011; Ochsner et al. 2013; Dumedah and Coulibably 2013; Ford et al. 2015; Sehgal et al. 2017); however, these studies are limited in scope (either spatially or temporally) because historically there has been relatively little effort devoted to assembling and homogenizing in situ soil moisture measurements for national-scale monitoring. Therefore, the lack of in situ soil moisture for large-scale monitoring efforts is less an indictment of the importance of in situ observations and more reflective of the historically deficient in situ monitoring infrastructure in the United States.

In response to this need, the National Soil Moisture Network (NSMN) community (https://www.drought.gov/drought/datagallery/national-soil-moisture-network) was tasked with building up the United States' in situ soil moisture monitoring capabilities while simultaneously improving the usability of our existing soil moisture monitoring infrastructure (Clayton et al. 2019). During the NSMN workshop in June 2016, near-realtime, national soil moisture datasets that integrate in situ, satellite-derived, and model-derived soil moisture were identified as the highest priority by the workshop participants (McNutt et al. 2016). There was a broad consensus among the 52 workshop participants who represented a variety of federal and state agencies, universities, and the private sector that a high-resolution gridded soil moisture product that leverages multiple soil moisture data sources is needed. Their sentiment reflects how critical in situ soil moisture observations are for national-scale monitoring, as well as for calibrating and validating the suite of satellite- and model-based soil moisture products.

As a result of the ongoing NSMN effort and other previous initiatives, the foundation has been laid for a high-resolution, near-real-time gridded soil moisture product that utilizes multiple in situ networks, satellite platforms, and land surface models. An important precursor to the development of this type of product is a comprehensive, national-scale assessment of in situ soil moisture data fidelity. Additionally, evaluation of the United States current in situ soil moisture monitoring infrastructure can inform satellite and model validation and benchmarking. Many previous studies have used in situ observations for satellite and model validation without ensuring the fidelity of these ground "truth" observations.

To address this critical knowledge gap, this study employs triple collocation to evaluate the fidelity of in situ soil moisture observations from over 1200 stations across the contiguous United States. The primary goal of the study is to determine the monitoring stations that are best suited for 1) inclusion in the NSMN, 2) deriving in situ-informed gridded soil moisture products, and 3) validating and benchmarking satellite- and model-derived soil moisture data. This is the first study to complete an in situ data validation effort at this scale in the United States.

\section{Data and methods}

\section{a. In situ soil moisture}

Daily in situ soil moisture observations from 1233 stations that are part of 15 monitoring networks (Table 1, Fig. 1) were downloaded in January and June 2020 from nationalsoilmoisture.com. These networks included the U.S. Climate Reference Network (CRN, https://www.ncdc.noaa.gov/crn/), Delaware Environmental Observing System (DEOS, http://www.deos.udel.edu/data/), North Carolina Environment and Climate Observing Network (ECONet, https://climate.ncsu.edu/econet), Illinois Climate Network (ICN, https://www.isws.illinois.edu/warm/), Kansas Mesonet (KS Mesonet, https://mesonet.k-state.edu/), New Jersey Weather and Climate Network (NJWCN, https:// www.njweather.org/), NOAA Hydrometeorological Testbed (NOAA HMT, https:/hmt.noaa.gov/), New York Mesonet (NY Mesonet, http://www.nysmesonet.org/), Oklahoma Mesonet (OK Mesonet, http://mesonet.org/), Soil Climate Analysis Network (SCAN, https://www.wcc.nrcs.usda.gov/scan/), South Dakota Mesonet (SD Mesonet, https://climate.sdstate.edu/), Snowpack Telemetry (SNOTEL, https://www.wcc.nrcs.usda.gov/ snow/), Texas Soil Observation Network (TxSon, https:// www.beg.utexas.edu/research/programs/txson), Georgia Automated Environmental Monitoring Network (GA AEMN, http:// www.georgiaweather.net/), and West Texas Mesonet (WTX Mesonet, http://www.depts.ttu.edu/nwi/research/facilities/wtm/ index.php).

We selected stations from all networks in the United States from which data were available. Stations were included if they had at least one year of valid (i.e., not missing) soil moisture measurements. This meant that we did not include stations with fewer than 365 valid observations, nor did we include networks that had a majority of stations with fewer than 365 valid observations. The 1-yr threshold was determined based on results of previous studies using similar evaluation methods (e.g., Dirmeyer et al. 2016; Ford and Quiring 2019), which found that short soil moisture data records exhibited high variability in temporal stability. Therefore, stations with records shorter than 365 days were not included in this study. All in situ data were acquired in units of volumetric water content $\theta\left(\mathrm{m}^{3} \mathrm{~m}^{-3}\right)$, and represent the original data from the networks with no additional quality control. A general overview of each in situ network is included in Table 1 and station locations are shown in Fig. 1. It is important to note that the number of stations from each network used in this study (and reported in 


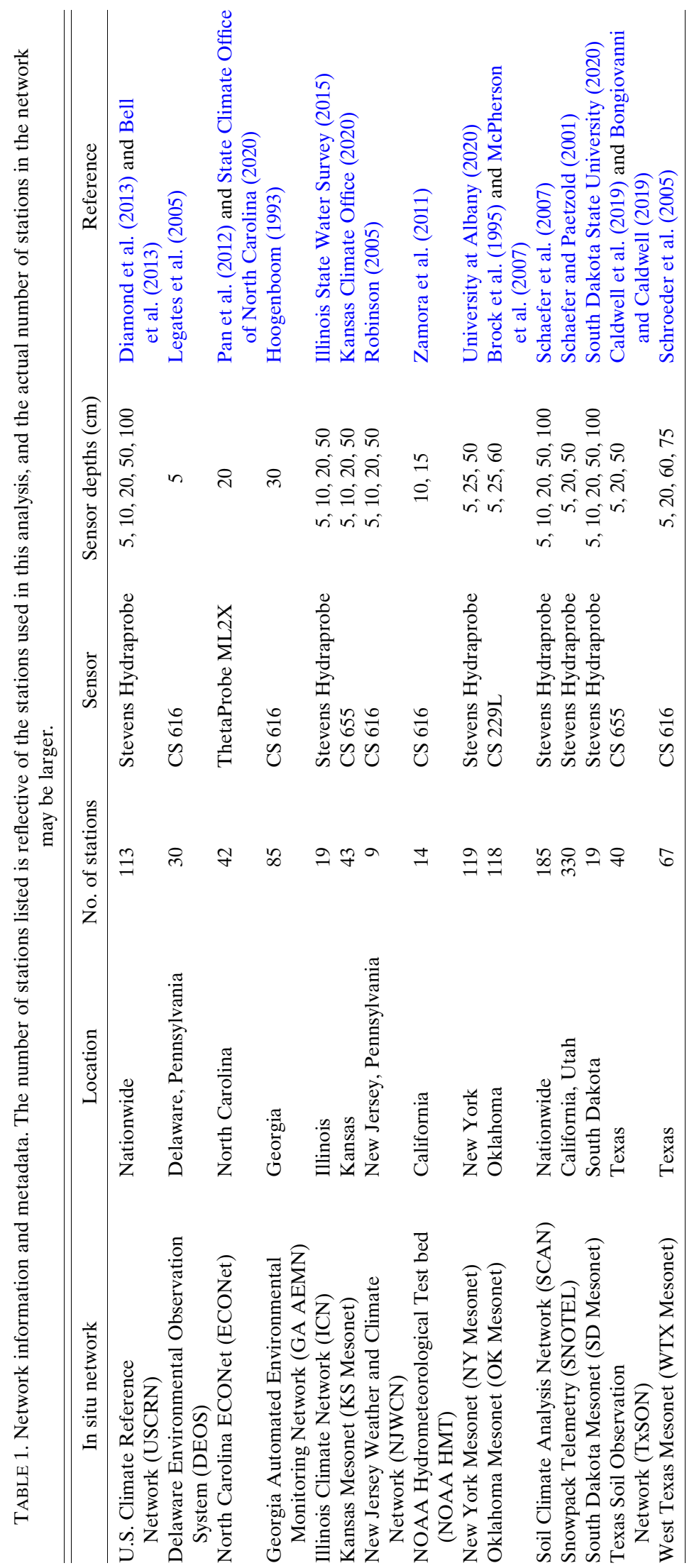




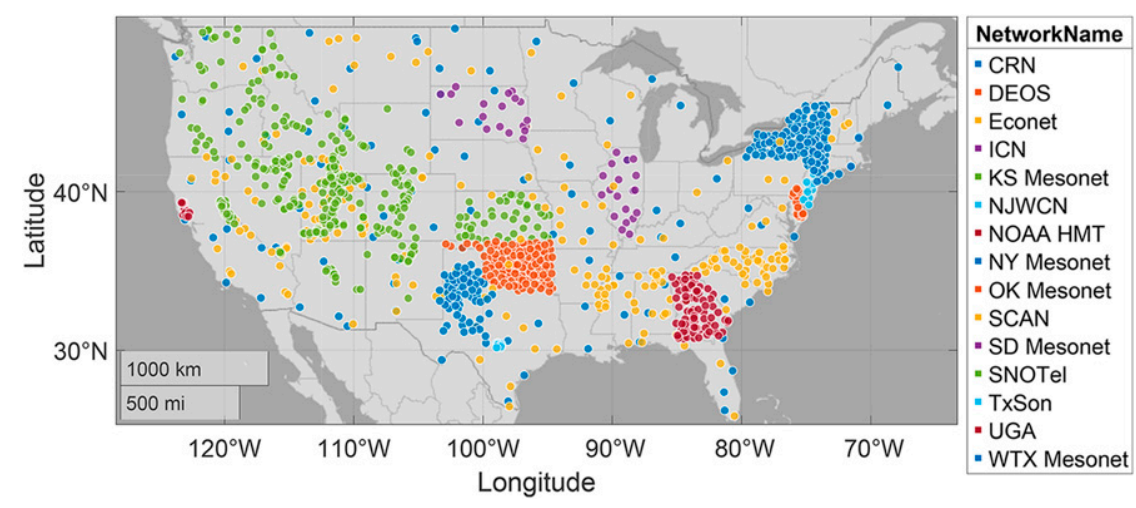

FIG. 1. Station locations by network.

Table 1) does not necessarily reflect the total number of stations in that network, as some stations' records were not sufficient for inclusion in this study.

\section{b. Land cover}

We use the U.S. Department of Agriculture (USDA) Cropland Data Layer (CDL, https://www.nass.usda.gov/ Research_and_Science/Cropland/SARS1a.php) to characterize land use and land cover surrounding the in situ observation stations. The CDL is a $30 \mathrm{~m}$, national-scale dataset that is specifically focused for agricultural land use (Boryan et al. 2011; Sandborn et al. 2019). It is produced from a supervised classification of land cover using both optical remote sensing and ground reference data collected from the USDA Farm Service Agency. The CDL includes many of the traditional land cover classes in the National Land Cover Database, such as grass, shrubland, and deciduous and evergreen forest; however, the benefit of using the CDL is its numerous agricultural land cover classes, such as corn, winter wheat, soybeans, and cotton.

We extracted CDL land cover information within the Noah land surface model grid cell in which each in situ station was situated. The geographic size of this area is approximately $156 \mathrm{~km}^{2}$, and information extracted represents land cover within a moderate spatial scale area surrounding the station. Specifically, we extracted two quantities from the CDL: 1) the land cover classes that represent the largest percentage of the area surrounding the in situ station, and 2 ) the total number of individual land cover classes represented within that area. We use the 2019 version of the CDL for this study; however, crop rotations and longer-term changes in land use could affect the type of land cover surrounding each station. Therefore, we performed a sensitivity analysis using the CDL from 2018, 2017, 2010, and 2009. The results using these CDL layers were quantitatively similar to that from the 2019 layer. We also compared these results to those from extracting CDL information using a larger $625 \mathrm{~km}^{2}$ area surrounding the in situ station, which was consistent with the size of the satellite remote sensing pixel used in the triple collocation analysis. The results (not shown) were also quantitatively similar to those using the land surface model pixel size.

\section{c. Triple collocation for in situ validation}

Triple collocation characterizes the total anomaly error of the in situ observations with respect to two independent soil moisture datasets, in this case soil moisture from a land surface model and satellite. Implemented in this manner, triple collocation can assess the consistency between in situ, point-based observations and soil moisture information over a larger spatial area (e.g., $\sim 10-50 \mathrm{~km}$ ), represented by the model and satellite products. The triple collocation error model is defined as

$$
i=\alpha_{i}+\beta_{i} \theta+\varepsilon_{i},
$$

where $i \in[X, Y, Z]$ are three spatially and temporally collocated soil moisture datasets. The unknown, true soil moisture is given by $\theta$, while $\alpha_{i}$ and $\beta_{i}$ are systematic gains of dataset $i$ with respect to $\theta$. Prior to computing the error variance, two of the soil moisture datasets must be rescaled with respect to the third dataset. Numerous rescaling techniques have been developed and applied for this purpose in the literature, including linear regression and variance matching. However, Yilmaz and Crow (2013) demonstrate that triple collocation is the only method that provides consistent, unbiased estimates of scaling coefficients, particularly in the case of variable signal-to-noise ratios between soil moisture datasets. Therefore, we use triple collocation to estimate scaling factors for the model $X$ and satellite $Z$ datasets to scale them to the reference data, which in this case are the in situ observations $Y$. Following the notation of Gruber et al. (2017), the rescaling coefficients $\beta_{i}^{*}$ are calculated as

$$
\begin{aligned}
& \beta_{Y}^{*}=\frac{\langle(X-\bar{X})(Z-\bar{Z})\rangle}{\langle(Y-\bar{Y})(Z-\bar{Z})\rangle} \\
& \beta_{Z}^{*}=\frac{\langle(X-\bar{X})(Y-\bar{Y})\rangle}{\langle(Z-\bar{Z})(Y-\bar{Y})\rangle} .
\end{aligned}
$$

The overbar denotes the mean of each times series, and the angled brackets \langle\rangle represent the average of the cross-multiplied differences. The model and satellite datasets are then rescaled such that

$$
\begin{aligned}
& \theta_{Y}=\beta_{Y}^{*}(Y-\bar{Y})+\bar{X}, \\
& \theta_{Z}=\beta_{Z}^{*}(Z-\bar{Z})+\bar{X},
\end{aligned}
$$


where $\theta_{Y}$ and $\theta_{Z}$ represent the rescaled measurements of the model and satellite datasets, respectively. Loew and Schlenz (2011) found that the representativity of in situ measurements for (satellite) pixel-scale soil moisture is time varying, particularly at the seasonal scale. Therefore, we follow the approach of Miralles et al. (2010) and deseasonalize soil moisture observations prior to rescaling. Specifically, we subtract from each daily soil moisture measurement the average of all days in the calendar month in which each measurement was taken, thereby accounting for the time varying nature of triple collocation error estimates.

In this study we use the European Space Agency Program on Global Monitoring of Essential Climate Variables (ESA-CCI, Liu et al. 2012; Dorigo et al. 2017; Gruber et al. 2017) satellite remote sensing soil moisture dataset and the Noah land surface model (Chen et al. 1996) soil moisture dataset for the TC analysis. ESA-CCI is a merged active-passive product that has a relatively long data record (1992-2019) and a $0.25^{\circ}$ horizontal resolution. We use the ESA-CCI dataset in this study instead of an individual platform such as Soil Moisture Active Passive (SMAP; Entekhabi et al. 2010) or Soil Moisture and Ocean Salinity (SMOS L3; Kerr et al. 2010) because of their relatively short data records $(\sim 5$ years and $\sim 11$ years, respectively). ESA-CCI provides daily soil moisture observations in units of volumetric water content $\left(\mathrm{m}^{3} \mathrm{~m}^{-3}\right)$. The Noah soil moisture dataset, which is part of the National Land Data Assimilation System (NLDAS-2, Xia et al. 2012) was selected as a third independent soil moisture source because 1) it has been previously shown to have high data fidelity (Xia et al. 2015; Ford and Quiring 2019), and 2) NLDAS-2 soil moisture data are available since 1979 and this covers the entire period of record for the in situ and satellite data. Noah simulates hourly soil moisture at multiple depths. Here we use $0-10-, 10-40-$, and 40-100-cm layers. The spatial resolution of NLDAS-2 is $1 / 8^{\circ}$. Hourly volumetric water content fields from Noah were averaged to daily to match the temporal resolution of the in situ and satellite datasets. It is important to note that neither ESA-CCI nor Noah use any of the in situ observations for their product calibration, therefore all three datasets are independent.

Mean random errors $e_{i}$ are calculated for each dataset (in situ, ESA-CCI, Noah) using the rescaled measurements from Eq. (2) such that

$$
e_{x}=\left\langle\left(\theta_{x}-\theta_{y}\right)\left(\theta_{x}-\theta_{z}\right)\right\rangle,
$$

where $e_{x}$ is the mean random anomaly error $\left(\mathrm{RAE} ; \mathrm{m}^{3} \mathrm{~m}^{-3}\right)$ of dataset $x$, and $\theta_{x}, \theta_{y}$, and $\theta_{z}$ are rescaled measurements from datasets $x, y$, and $z$, respectively. Similar to Eq. (2) the angled brackets represent the averaging of the cross-multiplied differences.

Triple collocation is often used to characterize upscaling errors in sparse in situ soil moisture measurements and provides a fair evaluation of coarse-scale remote sensing datasets by removing these upscaling errors (Loew and Schlenz 2011; Miralles et al. 2010). Miralles et al. (2010) in particular found that the triple collocation approach can estimate point-to-footprint soil moisture sampling errors to within $0.00059\left(\mathrm{~m}^{3} \mathrm{~m}^{-3}\right)$, which is then traditionally removed to provide a fairer validation of

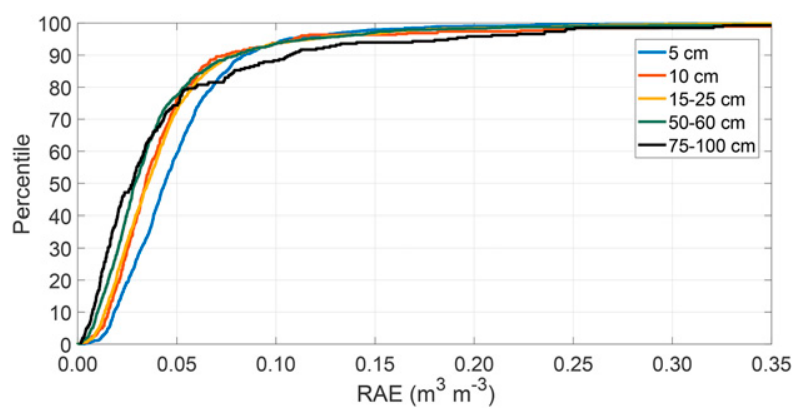

FIG. 2. Cumulative distribution functions of RAE for all stations in all networks evaluated. Distributions show stations grouped by measurement depth.

the remote sensing products. In this study we use a triple collocation approach similar to that of Miralles et al. (2010) and Chen et al. (2017), but instead focus on the in situ errors associated with point-based sampling of an area the size of a typical grid cell/pixel. Specifically, sensors and stations with low RAE values are in general more strongly correlated with satellite and model datasets, which represent spatial variations in soil moisture at scales around $10-50 \mathrm{~km}$ and therefore are more beneficial for both 1) satellite and model calibration and validation, and 2) inclusion in a national-scale in situ-informed gridded soil moisture dataset such as that being developed as part of the NSMN effort (McNutt et al. 2016; Clayton et al. 2019). This strategy for large-scale in situ soil moisture quality assessment is similar to Gruber et al. (2013), but focused on both national-scale and mesoscale monitoring networks in the contiguous United States.

It is important to note that although low RAE implies stronger consistency between the three soil moisture datasets, it cannot be used to infer accuracy without a more comprehensive assessment of potential biases in each of the datasets. In addition, RAE provides insight about one aspect of in situ soil moisture data fidelity, spatial consistency. There are several other aspects of fidelity that are also important to consider for in situ observations, including data completeness, data record length, site management, and/or metadata reporting, and measurement accuracy. The last of these is typically assessed using a "true" measure of soil moisture such as a gravimetric measurement (e.g., Scott et al. 2013). However, the spatial consistency information provided by triple collocation is valuable for understanding in situ soil moisture error across the contiguous United States, and the local-to-national factors that explain the variations in error.

\section{Results}

\section{a. Broad random anomaly error patterns}

Distributions of RAE from the 1233 stations are considerably right skewed at all three depths (Fig. 2). There are differences in RAE distributions between measurement depths (Fig. 2). The 5-cm observations exhibit a statistically significantly $(\alpha=0.05)$ higher median RAE than observations deeper in the soil column, based on a Kolmogorov-Smirnov 

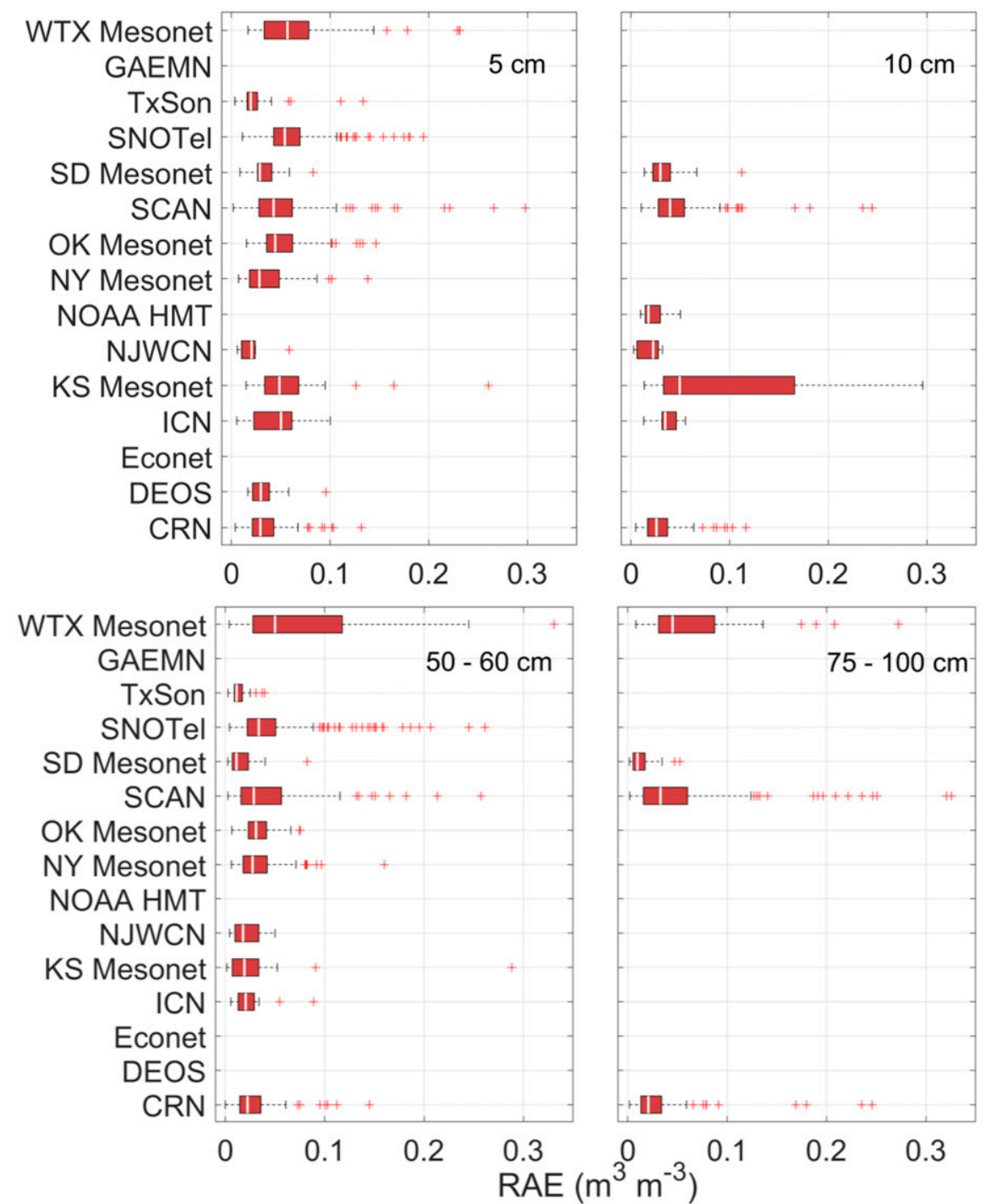

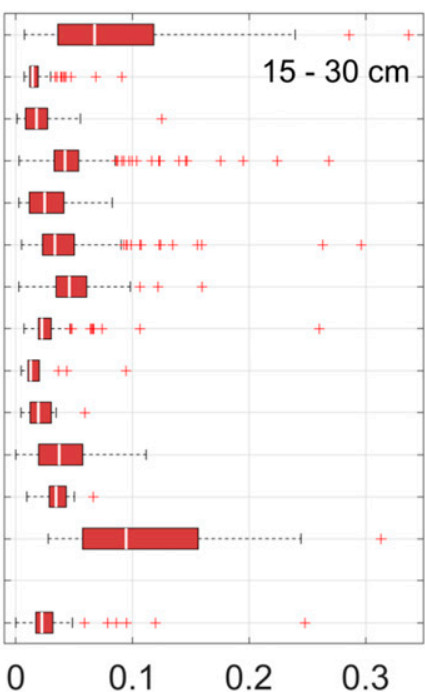

$\begin{array}{llll}0 & 0.1 & 0.2 & 0.3\end{array}$

FIG. 3. Boxplots show distributions of $\operatorname{RAE}\left(\mathrm{m}^{3} \mathrm{~m}^{-3}\right)$ for all stations within each network. The network median RAE is shown in the white line.

two-sample test. As we discuss later in the paper, local-scale differences in land cover contribute more to differences in 5-cm RAE than they do to deeper soil moisture measurements. Based on analysis using far fewer stations, Ford and Quiring (2019) imposed a RAE threshold of $0.15 \mathrm{~m}^{3} \mathrm{~m}^{-3}$ when determining stations with adequate data fidelity for satellite/model validation. However, our analysis indicates that over $90 \%$ of stations evaluated in this study have a RAE less than $0.10 \mathrm{~m}^{3} \mathrm{~m}^{-3}$. This suggests that most stations monitoring soil moisture in the contiguous United States exhibit high spatial consistency with larger-scale representations of soil moisture. All the RAE distributions have large outliers (Fig. 2), and there are statistically significant differences in RAE between networks (Fig. 3), suggesting that factors other than measurement depth also influence data fidelity. We further analyze RAE to identify what is responsible for causing the outliers.
The data record length of in situ soil moisture observations is an important aspect of data fidelity, because of the potential instability of anomalies calculated from relatively short data records (e.g., Ford et al. 2016). However, RAE at the 1233 stations assessed in this study does not vary as a statistically significant function of data record length (Fig. 4). This finding is consistent at all measurement depths. In addition, further analysis (not shown) indicates RAE does not significantly vary as a function of soil type or measurement sensor (e.g., heat dissipation versus impedance dielectric). Figure 5 shows the national-scale spatial variability of RAE at each measurement depth increment. There are no apparent spatial patterns in RAE that would imply effects of large-scale drivers such as aridity, climatological precipitation variability, or air temperature range and variability. However, we do find statistically significant differences in the median RAE grouped by surrounding land cover, which is discussed in the following section. 

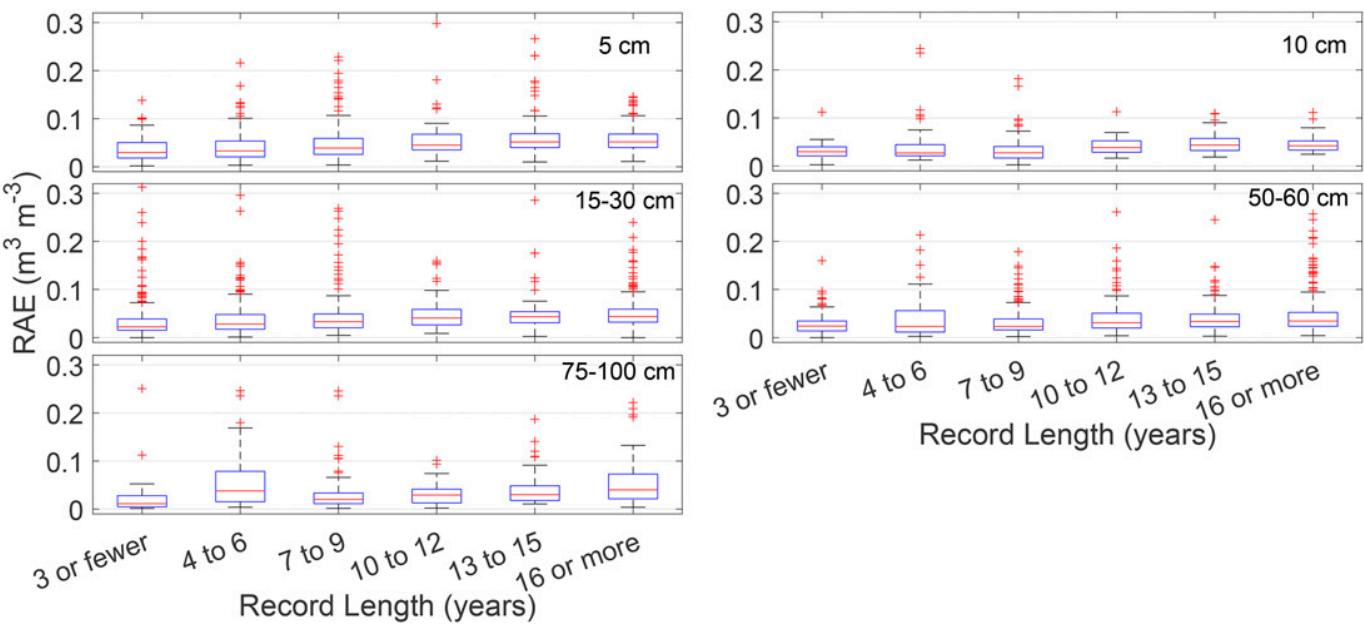

FIG. 4. RAE grouped by observation record length for each depth interval. The red line in the center of each box indicates the group median.

\section{b. Land cover impacts}

The 2019 USDA Crop Data Layer is used to assess land use and land cover within an approximately $156 \mathrm{~km}^{2}$ region surrounding each in situ station resides. Specifically, we examined 1) the land cover that makes up the largest proportion of the area surrounding the station and 2) the land cover variability-in this case the number of different land cover classes within the surrounding area. When stations are grouped by land cover, a one-way analysis of variance (ANOVA) finds statistically significant $(\alpha=0.05)$ differences in RAE between groups. Multiple comparison tests, summarized by Fig. 6, indicate stations surrounded by cotton and winter wheat exhibit significantly higher RAE. In addition, the differences between land cover types are greatest at shallower measurement depths and tend to be least in the 50-60- and 75-100-cm observations.

The ANOVA results and boxplots in Fig. 6 suggest the land cover surrounding in situ stations does influence RAE and therefore the spatial consistency of those in situ observations with larger-scale soil moisture datasets. However, it is unclear from this analysis if these variations are confounded by differences in network-specific factors such as sensor calibration, installation procedures, or data quality control. To better isolate and diagnose the modulating role of land cover, we assess RAE by land cover type separately for two networks, which both exhibit a relatively large range of station RAE values: the ECONet and WTX Mesonet networks.

WTX Mesonet stations have a high network-average RAE compared to other networks (Fig. 3). All WTX Mesonet stations are sited in either grassland or shrubland, but 30 of the 67 WTX Mesonet stations are surrounded by winter wheat or irrigated cotton. Like the national-scale land cover analysis (Fig. 6), RAE at WTX Mesonet stations varies significantly as a function of surrounding land cover according to a one-way ANOVA. Specifically, the median RAE of stations surrounded

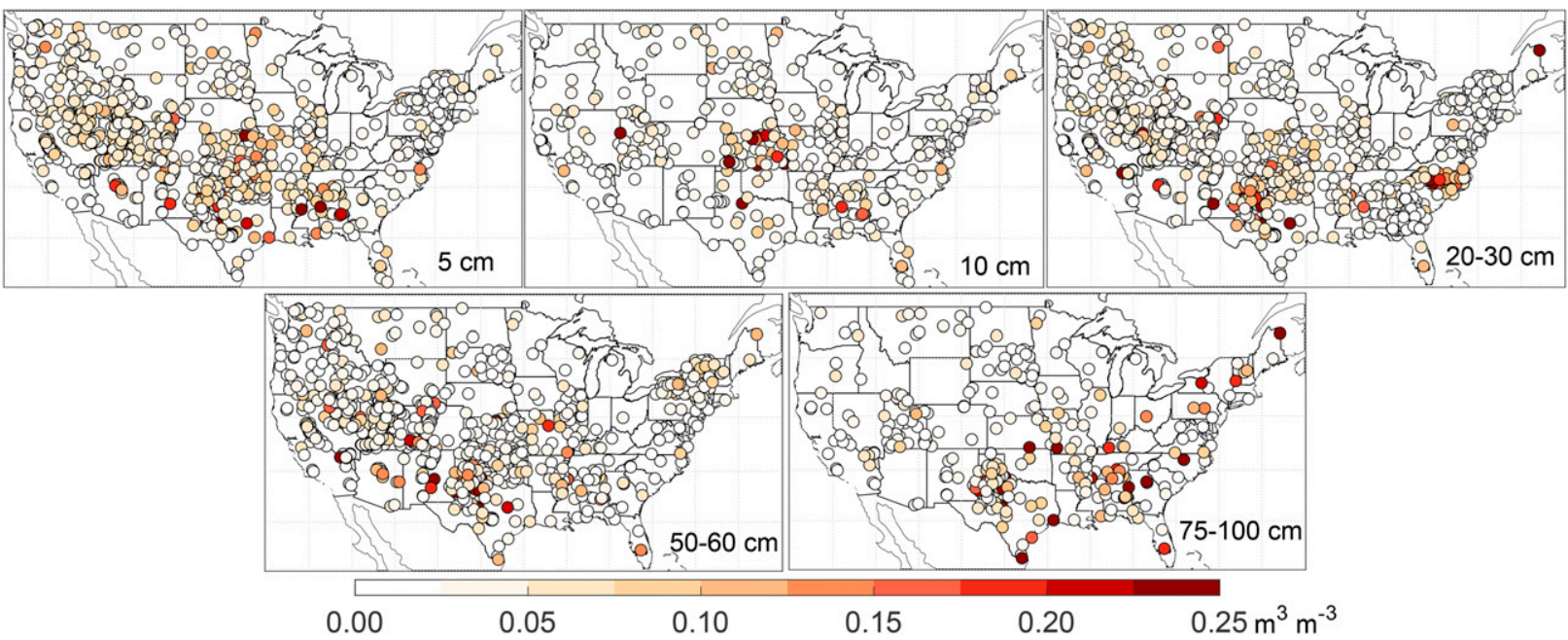

FIG. 5. Maps show RAE by measurement depth for all 1233 stations across the United States. 


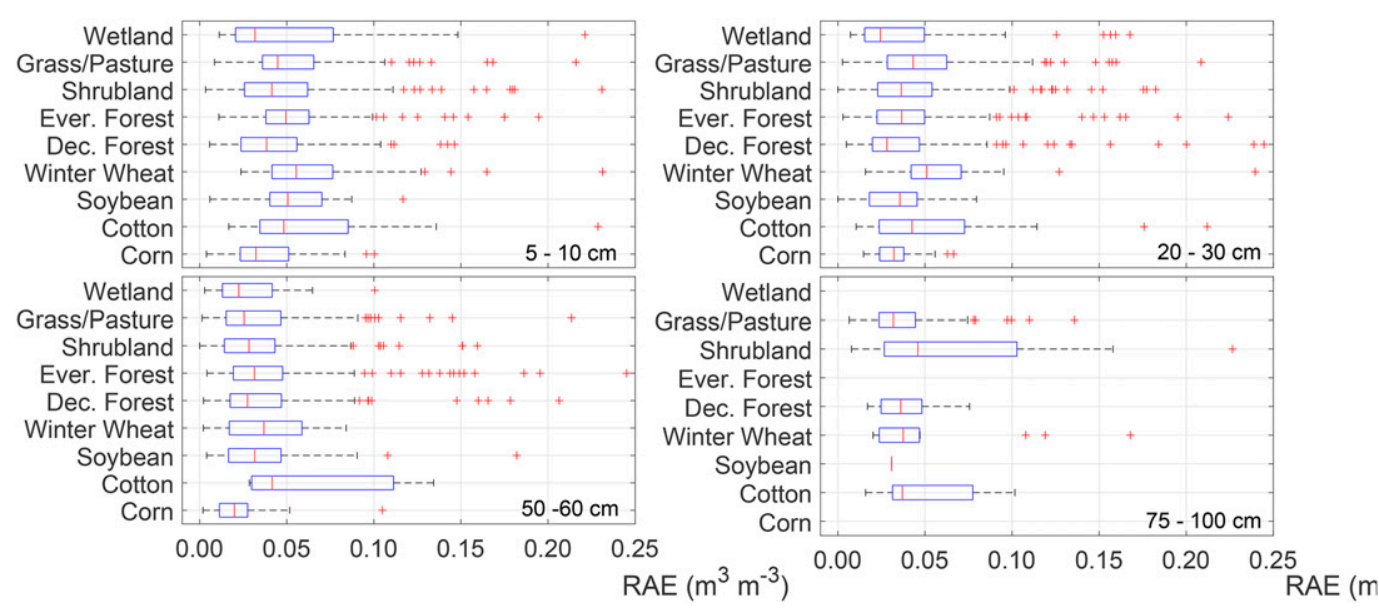

FIG. 6. Boxplots show RAE grouped by land cover surrounding each station. All 1233 stations are represented in the boxplots, which are shown by measurement depth.

by winter wheat is significantly higher than those of surrounded by cotton, shrubland, and grass/pasture (Fig. 7). Previous studies have documented issues with representing soil moisture in predominantly winter wheat landscapes using observations from stations sited in nonagricultural land cover (Patrignani and Ochsner 2018). The differences between land cover tend to decrease with measurement depth and are not statistically significant at either the 60 - or $75-\mathrm{cm}$ depths for WTX Mesonet stations. Interestingly, RAE at stations in the other two networks with a nonnegligible number of stations sited in predominantly winter wheat land cover, the Oklahoma Mesonet and Kansas Mesonet, also display a noticeable increase over stations with other surrounding land cover types that are not winter wheat; however, these differences are neither to the same extent as the WTX Mesonet nor statistically significant.
This is despite the soil moisture representativeness issues in winter wheat landscapes reported by Patrignani and Ochsner (2018) using Oklahoma Mesonet observations.

Another interesting finding from the WTX Mesonet analysis is that stations sited in nonirrigated grass or shrubland and surrounded by irrigated cotton fields did not experience a noticeable increase in RAE as compared to stations where the land cover at the site was consistent with their surroundings (Fig. 6). Only three of these stations-Wall, St. Lawrence, and Memphis-had RAE $>0.10$ at any measurement depth. According to Wes Burgett of the WTX Mesonet, these three stations suffer from a multitude of issues that likely affect their spatial representativeness, including irrigation runoff (W. Burgett 2020, personal communication). Therefore, the high RAE at these three sites is likely due to poor siting with
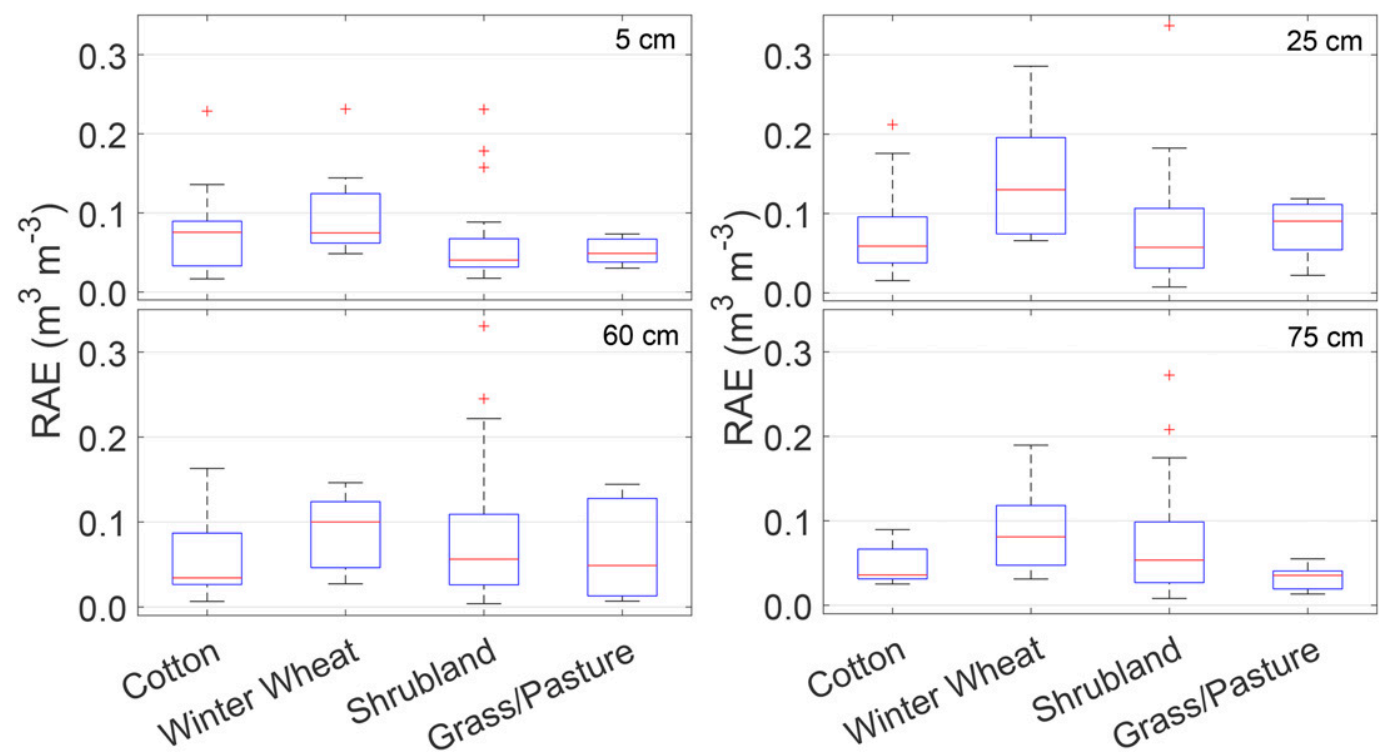

FIG. 7. Boxplots show RAE grouped by land cover surrounding each West Texas Mesonet station. Boxplots are shown by measurement depth. 

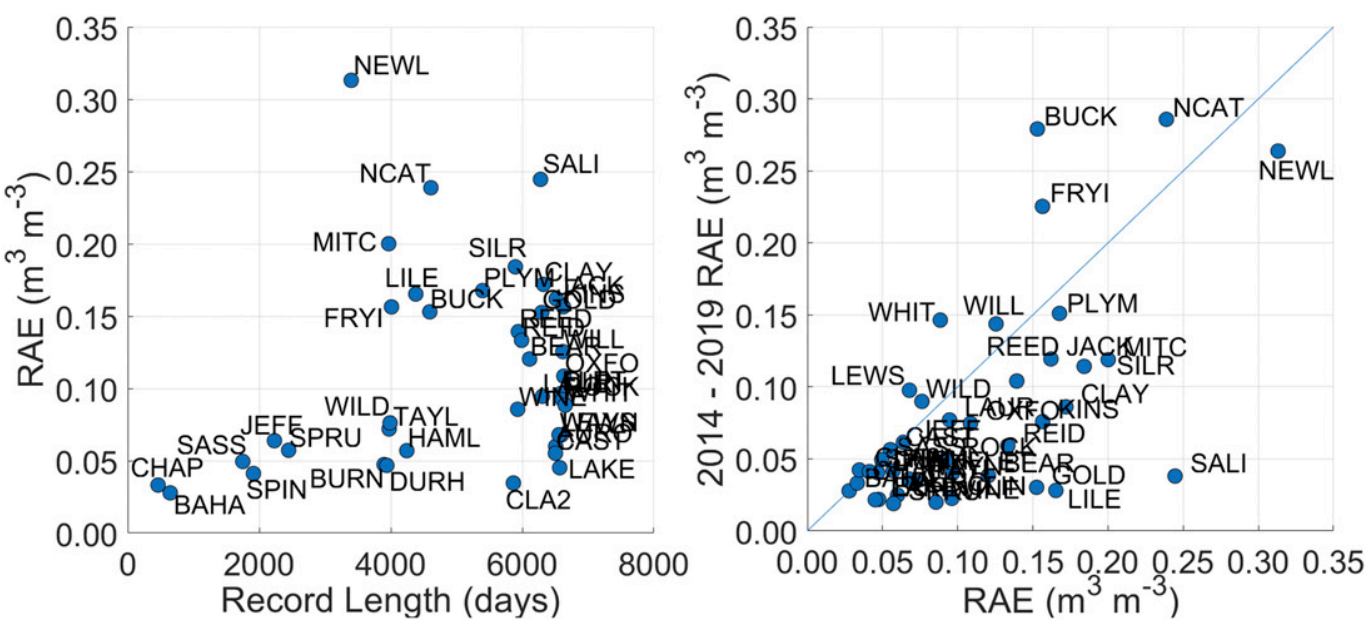

FIG. 8. (left) Scatterplot showing 10-40-cm RAE and observation record length (days) at each North Carolina ECONet station. (right) Scatterplot showing 10-40-cm RAE from each ECONet station computed over the entire observation record ( $x$ axis) and computed only using observations from 2014 to 2019 ( $y$ axis).

respect to local hydrology rather than the surrounding land cover. Outside of land cover impacts, high RAE at Aspermont (grass/pasture land cover) and Goodlett (shrubland land cover) stations of the WTX Mesonet are likely due to damage to the sensors from animals (W. Burgett 2020, personal communication).

ECONet exhibits the highest network-average 15-30-cm RAE. This is the only soil layer in which ECONet monitors soil moisture. Most ECONet stations are sited in grassland, but surrounded by deciduous forest, evergreen forest, or wetlands. Unlike WTX Mesonet, the RAE for ECONet does not significantly vary as a function of land cover. Upon closer inspection, ECONet stations with shorter record lengths, particularly those less than 10 years, exhibited very low RAE, whereas stations with $10+$ years of observations exhibited a larger range of RAE values (Fig. 8a). While there is not a statistically significantly relationship between RAE and observation record length on a national scale (e.g., Fig. 4), it appears that this may have an influence on within network variations in RAE. According to Sean Heuser of the State Climate Office of North Carolina, ECONet began changing soil moisture sensors from the Decagon ECHO2x to the DeltaT ML3 sensor around 11 years ago (S. Heuser 2020, personal communication). We examined the influence of this sensor change by recomputing RAE at all ECONet stations using only observations from 2014 to 2019, after the ECHO2x sensors had been replaced. The results show that RAE computed over the shorter 6-yr period is lower than that computed over the entire observation record at most ECONet sites (Fig. 8b). At the Piedmont Research Station in Salisbury (i.e., SALI station), 10-40-cm RAE decreased from 0.24 to less than $0.05\left(\mathrm{~m}^{3} \mathrm{~m}^{-3}\right)$ when using only DeltaT ML3 observations. There are a few sites where the RAE did not change, or even increased, during the 2014-19 period. However, according to Sean Heuser, these sites are located in soils that are not representative of the surrounding areas (S. Heuser 2020, personal communication). This explains why they have high RAE values and why the RAE was unresponsive to sensor changes.

\section{Discussion and conclusions}

Soil moisture is a key variable for numerous scientific and nonscientific domains, and in situ soil moisture monitoring is a tremendous resource. However, relative to atmospheric variables such as temperature and precipitation, there are few in situ soil moisture stations across the contiguous United States. Large-scale in situ soil moisture monitoring efforts such as the International Soil Moisture Network (Dorigo et al. 2011) and the NSMN (McNutt et al. 2016) have provided the foundation for improving soil moisture monitoring globally and setting standards for continued expansion of monitoring infrastructure. As new in situ monitoring networks are created and existing networks expand their monitoring capability, it is critical to understand the quality and representativeness of the in situ observations, particularly for large-scale climate and drought monitoring and for the calibration/validation of land surface models and satellite soil moisture products.

This study represents the first attempt to assess the fidelity of in situ observations from more than 1200 stations across the United States as part of the National Soil Moisture Network effort. We use triple collocation to quantify in situ measurement random anomaly error and spatial consistency. Overall, we find that measurements at the vast majority of the assessed stations are generally of high quality based on this metric. For example, over $90 \%$ of the 3633 station depths assessed exhibit RAE under $0.10\left(\mathrm{~m}^{3} \mathrm{~m}^{-3}\right)$.

Triple collocation analysis revealed few obvious patterns in the large-scale factors influencing in situ observations spatial representativeness. Station RAE did significantly vary by measurement depth, with 5-cm measurements exhibiting a higher median RAE than other depths. However, RAE was relatively insensitive to observation record length, soil moisture sensor type, and soil texture. Furthermore, we did not find any apparent influence of frozen soils or sensor drift on RAE. 
The lack of significant patterns or trends of RAE by climate or soil is consistent with Gruber et al. (2013), who assessed in situ soil moisture fidelity using triple collocation across a similarly large region.

We did find statistically significant variations in RAE as a function of land cover. Specifically, stations sited in nonagricultural land cover, but largely surrounded by winter wheat exhibited significantly higher RAE than sites surrounded by nonwinter wheat land cover, including cotton, corn, and forest. The fact that stations surrounded by winter wheat exhibited high RAE is not necessarily surprising, given that the majority of in situ soil moisture observing stations in the United States, and approximately $96 \%$ of all stations examined here are sited in land cover that is best described as grassland or some other type of "natural" land cover such as shrubland. Particularly in forested and agricultural regions of the United States, the immediate land cover of the in situ site is not representative of larger-scale land use, and this discrepancy has been shown to affect in situ soil moisture representativeness (Han et al. 2012; Chen et al. 2017; Patrignani and Ochsner 2018). Patrignani and Ochsner (2018) point to asymmetry in the seasonality of soil moisture underlying grass with that underlying winter wheat in Oklahoma, driven by dissimilar vegetation phenology. Chen et al. (2017), based on a triple collocation analysis using SCAN and CRN stations, reported higher error (less spatially representative) at stations within pixels containing large water bodies or forests. In our larger sample of stations, we find surrounding land cover does influence in situ measurement upscaling error, but that this impact is larger over agricultural land than forests.

Our findings demonstrate that issues arise from the pervasive siting of in situ soil moisture monitoring stations in grassland, shrubland, or bare soil, which in many cases are not representative of the surrounding landscape. The mismatch and time-dependent relationship between soil moisture dynamics in grassland and agricultural land cover, such as winter wheat, force scientists to use models to derive the latter from the former (Han et al. 2012; Lollato et al. 2016; Krueger et al. 2019), or complete expensive field campaigns to better understand cropland soil moisture dynamics (e.g., Patrignani et al. 2012). In this study, the negative effects of station siting and land cover mismatches were limited to winter wheat, as RAE was seemingly unaffected at sites surrounded by corn, soybeans, or forest. Although the different phenology, rooting depths, and water use efficiencies of these crops will lead to varying soil moisture dynamics, this does not appear to influence the larger-scale spatial consistency of in situ observations.

We additionally found that site-specific characteristics were likely primary contributors to high RAE, at least at WTX Mesonet and ECONet stations. Specifically, several ECONet sites that had been operating for $10+$ years suffered from poor spatial representativeness linked to sensors that have been since replaced. ECONet sites that have come online more recently, with the newer sensors, do not experience the same high RAE values. A few WTX Mesonet sites not surrounded by winter wheat also exhibited high RAE, which was attributed to station siting in areas downhill of irrigated agriculture, and sensors being disturbed by animals.
Overall, our triple collocation analysis yielded two primary conclusions: 1 ) observations at the vast majority of the $1200+$ stations included exhibit low RAE and are therefore spatially consistent with model and satellite representations of larger scale (10-25 km) soil moisture, and 2) those stations that exhibit high anomaly error are likely influenced by unrepresentative land cover or site-specific factors that are difficult to detect. Low spatial consistency (i.e., high RAE) can create serious issues when using in situ observations to represent soil moisture over a larger area such as for drought monitoring, flood prediction and hydrologic/hydraulic modeling, and land surface model or satellite validation. Therefore, understanding the representativeness and reliability of sparse in situ stations for capturing satellite footprint scale soil moisture variability is important for appropriately evaluating the remote sensing dataset (e.g., Miralles et al. 2010; Chen et al. 2017). Given the results presented here, we recommend that applications utilizing in situ soil moisture data should either 1) use a method such as triple collocation to test the spatial consistency of the data they are using, or 2) contact the managers of the monitoring networks to gain insights about the station data, in order to ensure that the in situ observations that are being used are robust and spatially representative. The first option is useful in situations where the in situ stations used is sited under land cover that is not representative of the larger-scale surrounding land cover.

This study provides an evaluation of in situ observations at over 1200 stations across the contiguous United States as part of the NSMN effort. It demonstrates that the vast majority of stations exhibit high data fidelity, as assessed using triple collocation. It is important to note that the method used here assesses only one aspect of data fidelity and does not include measurement accuracy or data completeness. The stations with high error are affected by land cover and/or site-specific factors that are more difficult to identify. However, the stations exhibiting very high RAE represent a small fraction $(<10 \%)$ of all stations that were evaluated. The RAE values from every station and soil depth will be published on the National Soil Moisture website (https://nationalsoilmoisture.com), and these values will be updated regularly as more observations, stations, and networks come online.

Acknowledgments. This research is made possible by the New York State (NYS) Mesonet. Original funding for the NYS Mesonet was provided by Federal Emergency Management Agency Grant FEMA-4085-DR-NY, with the continued support of the NYS Division of Homeland Security and Emergency Services; the state of New York; the Research Foundation for the State University of New York (SUNY); the University at Albany, SUNY; the Atmospheric Sciences Research Center (ASRC) at SUNY Albany; and the Department of Atmospheric and Environmental Sciences (DAES) at SUNY Albany. Thank you to Sean Heuser and Wes Burgett for their help and expertise. David Kristovich (ISWS) reviewed this manuscript. This work was supported by NOAA Grant NA17OAR4310148.

Data availability statement. In situ observations as part of the USCRN, NOAA HMT, OK Mesonet, SCAN, SNOTEL, and WTX Mesonet are available at https://nationalsoilmoisture.com. 
DEOS observations are available at http://www.deos.udel.edu/ data/agirrigation_retrieval.php, ECONet observations are available at https://climate.ncsu.edu/econet, GA AEMN observations are available at https://georgiaweather.net, ICN observations are available at https://isws.illinois.edu/warm/soil, KS Mesonet observations are available at https://mesonet.kstate.edu, NJWCN observations are available at https:// njweather.org, NY Mesonet observations are available at https:// nysmesonet.org, SoilScape observations are available at http:// soilscape.usc.edu/bootstrap/sites_and_data.html, and SD Mesonet observations are available at https://mesonet.sdstate.edu.

\section{REFERENCES}

Bell, J. E., and Coauthors, 2013: U.S. Climate Reference Network soil moisture and temperature observations. J. Hydrometeor., 14, 977-988, https://doi.org/10.1175/JHM-D-12-0146.1.

Bongiovanni, T., and T. G. Caldwell, 2019: Texas Soil Observation Network (TxSON). Texas Data Repository Dataverse, V3, accessed 7 July 2020, https://doi.org/10.18738/T8/JJ16CF.

Boryan, C., Z. Yang, R. Mueller, and M. Craig, 2011: Monitoring US agriculture: The US department of agriculture, national agricultural statistics service, cropland data layer program. Geocarto Int., 26, 341-358, https://doi.org/10.1080/10106049.2011.562309.

Brocca, L., T. Moramarco, F. Melone, W. Wagner, S. Hasenauer, and S. Hahn, 2012: Assimilation of surface- and root-zone ASCAT soil moisture products into rainfall-runoff modeling. IEEE Trans. Geosci. Remote Sens., 50, 2542-2555, https:// doi.org/10.1109/TGRS.2011.2177468.

Brock, F. V., K. C. Crawford, G. W. Elliott, S. J. Cuperus, H. L. Johnson, and M. D. Eilts, 1995: The Oklahoma mesonet: A technical overview. J. Atmos. Oceanic Technol., 12, 5-19, https:// doi.org/10.1175/1520-0426(1995)012<0005:TOMATO>2.0.CO;2.

Caldwell, T. G., and Coauthors, 2019: The Texas soil observation network: A comprehensive soil moisture dataset for remote sensing and land surface model validation. Vadose Zone J., 18, 1-20, https://doi.org/10.2136/vzj2019.04.0034.

Champagne, C., A. Davidson, P. Cherneski, J. L'Heureux, and T. Hawden, 2015: Monitoring agricultural risk in Canada using L-band passive microwave soil moisture from SMOS. J. Hydrometeor., 16, 5-18, https://doi.org/10.1175/JHM-D-140039.1.

Chen, F., and Coauthors, 1996: Modeling of land surface evaporation by four schemes and comparison with FIFE observations. J. Geophys. Res., 101, 7251-7268, https://doi.org/10.1029/ 95JD02165.

— , and Coauthors, 2017: Application of triple collocation in ground-based validation of Soil Moisture Active/Passive (SMAP) level 2 data products. IEEE Appl. Earth Obs. Rem. Sens., 10, 489502, https://doi.org/10.1109/JSTARS.2016.2569998.

Clayton, J. A., S. M. Quiring, T. Ochsner, M. Cosh, B. Baker, T. W. Ford, J. D. Bolten, and M. Woloszyn, 2019: Building a onestop shop for soil moisture information. Eos, Trans. Amer. Geophys. Union, 100, https://doi.org/10.1029/2019EO123631.

Crow, W. T., and Coauthors, 2012: Upscaling sparse ground-based soil moisture observations for the validation of coarseresolution satellite soil moisture products. Rev. Geophys., 50, RG2002, https://doi.org/10.1029/2011RG000372.

_ F. Chen, R. H. Reichle, Y. Xia, and Q. Liu, 2018: Exploiting soil moisture, precipitation, and streamflow observations to evaluate soil moisture/runoff coupling in land surface models. Geophys. Res. Lett., 45, 4869-4878, https://doi.org/10.1029/ 2018 GL077193. de Rosnay, P., G. Balsamo, C. Albergel, J. Muñoz-Sabater, and L. Isaksen, 2014: Initialization of land surface variables for numerical weather prediction. Surv. Geophys., 35, 607-621, https://doi.org/10.1007/s10712-012-9207-x.

Diamond, H. J., and Coauthors, 2013: U.S. Climate Reference Network after one decade of operations: Status and assessment. Bull. Amer. Meteor. Soc., 94, 485-498, https://doi.org/ 10.1175/BAMS-D-12-00170.1.

Dirmeyer, P. A., and Coauthors, 2016: Confronting weather and climate models with observational data from soil moisture networks over the United States. J. Hydrometeor., 17, 10491067, https://doi.org/10.1175/JHM-D-15-0196.1.

— C. A. Schlosser, and K. L. Brubaker, 2009: Precipitation, recycling, and land memory: An integrated analysis. J. Hydrometeor., 10, 278-288, https://doi.org/10.1175/2008JHM1016.1.

Dorigo, W. A., and Coauthors, 2011: The International Soil Moisture Network: A data hosting facility for global in situ soil moisture measurements. Hydrol. Earth Syst. Sci., 15, 16751698, https://doi.org/10.5194/hess-15-1675-2011.

_, and Coauthors, 2017: ESA CCI soil moisture for improved Earth system understanding: State-of-the art and future directions. Remote Sens. Environ., 203, 185-215, https://doi.org/ 10.1016/j.rse.2017.07.001.

Dumedah, G., and P. Coulibably, 2013: Evolutionary assimilation of streamflow in distributed hydrologic modeling using in-situ soil moisture data. Adv. Water Resour., 53, 231-241, https:// doi.org/10.1016/j.advwatres.2012.07.012.

Entekhabi, D., and Coauthors, 2010: The Soil Moisture Active Passive (SMAP) mission. Proc. IEEE, 98, 704-716, https:// doi.org/10.1109/JPROC.2010.2043918.

Fan, Y., and H. van Den Dool, 2004: Climate Prediction Center global monthly soil moisture data set at $0.5^{\circ}$ resolution for 1948 to present. J. Geophys. Res., 104, D10102, https://doi.org/ 10.1029/2003JD004345.

Flores, A. N., D. Entekhabi, and R. L. Bras, 2014: Application of a hillslope-scale soil moisture data assimilation system to military trafficability assessment. J. Terramech., 51, 53-66, https:// doi.org/10.1016/j.jterra.2013.11.004.

Ford, T. W., and C. F. Labosier, 2017: Meteorological conditions associated with the onset of flash drought in the eastern United States. Agric. For. Meteor., 247, 414-423, https://doi.org/ 10.1016/j.agrformet.2017.08.031.

— model, and satellite remote sensing soil moisture with a focus on drought monitoring. Water Resour. Res., 55, 1565-1582, https://doi.org/10.1029/2018WR024039.

— D. B. McRoberts, S. M. Quiring, and R. E. Hall, 2015: On the utility of in situ soil moisture observations for flash drought early warning in Oklahoma. Geophys. Res. Lett., 42, 97909798, https://doi.org/10.1002/2015GL066600.

—, Q. Wang, and S. M. Quiring, 2016: The observation record length necessary to generate robust soil moisture percentiles. J. Appl. Meteor. Climatol., 55, 2131-2149, https://doi.org/ 10.1175/JAMC-D-16-0143.1.

$\longrightarrow$, P. A. Dirmeyer, and D. O. Benson, 2018: Evaluation of heat wave forecasts seamlessly across subseasonal timescales. NPJ Climate Atmos. Sci., 1, 20, https://doi.org/10.1038/s41612-0180027-7.

Gruber, A., W. A. Dorigo, S. Zwieback, A. Xaver, and W. Wagner, 2013: Characterizing coarse-scale representativeness of in situ soil moisture measurements from the International Soil Moisture Network. Vadose Zone J., 12, 1-16, https://doi.org/ 10.2136/vzj2012.0170. 
,-- W. Crow, and W. Wagner, 2017: Triple collocationbased merging of satellite soil moisture retrievals. IEEE Trans. Geosci. Remote Sens., 55, 6780-6792, https://doi.org/ 10.1109/TGRS.2017.2734070.

Guo, Z., P. A. Dirmeyer, and T. DelSole, 2011: Land surface impacts on subseasonal and seasonal predictability. Geophys. Res. Lett., 38, L24812, https://doi.org/10.1029/2011GL049945.

Han, E., G. C. Heathman, V. Merwade, and M. H. Cosh, 2012: Application of observation operators for field scale soil moisture averages and variances in agricultural landscapes. J. Hydrol., 444-445, 34-50, https://doi.org/10.1016/j.jhydrol.2012.03.035.

Hoogenboom, G., 1993: The Georgia automated environmental monitoring network. Georgia Institute of Technology, 5 pp., http://www.gwri.gatech.edu/sites/default/files/files/docs/1993/ HoogenboomG-93.pdf.

Illinois State Water Survey, 2015: Illinois Climate Network. Water and Atmospheric Resources Monitoring Program, https:// doi.org/10.13012/J8MW2F2Q.

Kansas Climate Office, 2020: Kansas Mesonet Historical Data. Accessed 5 January 2020, https://mesonet.k-state.edu/weather/ historical.

Kerr, Y., and Coauthors, 2010: The SMOS mission: New tool for monitoring key elements of the global water cycle. Proc. IEEE, 98, 666-687, https://doi.org/10.1109/JPROC.2010.2043032.

Koster, R. D., and Coauthors, 2011: The second phase of the global land-atmosphere coupling experiment: Soil moisture contributions to subseasonal forecast skill. J. Hydrometeor., 12, 805822, https://doi.org/10.1175/2011JHM1365.1.

Krueger, E. S., T. E. Ochsner, and S. M. Quiring, 2019: Development and evaluation of soil moisture-based indices for agricultural drought monitoring. Agron. J., 111, 1392-1406, https://doi.org/ 10.2134/agronj2018.09.0558.

Legates, D., and Coauthors, 2005: DEOS: The Delaware Environmental Observing System. 21st Int. Conf. on Interactive Information Processing Systems (IIPS) for Meteorology, Oceanography, and Hydrology, San Diego, CA, Amer. Meteor. Soc., 18.10, https://ams.confex.com/ams/Annual2005/techprogram/paper_ 87687.htm.

Liu, Y. Y., W. A. Dorigo, R. M. Parinussa, R. A. M. de Jeu, W. Wagner, M. F. McCabe, J. P. Evans, and A. I. J. M. van Dijk, 2012: Trend-preserving blending of passive and active microwave soil moisture retrievals. Remote Sens. Envion., 123, 280297, https://doi.org/10.1016/j.rse.2012.03.014.

Lloyd, C. E. M., J. E. Freer, P. J. Johnes, and A. L. Collins, 2016: Using hysteresis analysis of high-resolution water quality monitoring data, including uncertainty, to infer controls on nutrient and sediment transfer in catchments. Sci. Total Environ., 543, 388-404, https://doi.org/10.1016/j.scitotenv.2015.11.028.

Loew, A., and F. Schlenz, 2011: A dynamic approach for evaluating coarse scale satellite soil moisture products. Hydrol. Earth Syst. Sci., 15, 75-90, https://doi.org/10.5194/hess-15-75-2011.

Lollato, R. P., A. Patrignani, T. E. Ochsner, and J. T. Edwards, 2016: Prediction of plant available water at sowing for winter wheat in the Southern Great Plains. Agron. J., 108, 745-757, https://doi.org/10.2134/agronj2015.0433.

Lorenz, R., E. B. Jaeger, and S. I. Seneviratne, 2010: Persistence of heat waves and its link to soil moisture memory. Geophys. Res. Lett., 37, L09703, https://doi.org/10.1029/2010GL042764.

Mahanama, S. P., R. D. Koster, R. H. Reichle, and L. Zubair, 2008: The role of soil moisture initialization in subseasonal and seasonal streamflow prediction-A case study in Sri Lanka. Adv. Water Resour., 31, 1333-1343, https://doi.org/10.1016/ j.advwatres.2008.06.004.
McNutt, C., M. Strobel, J. Lucido, and S. M. Quiring, 2016: National Soil Moisture Network Workshop 2016: Progress made, future directions. 8 pp., https://www.drought.gov/drought/ documents/national-soil-moisture-network-workshop-2016progress-made-future-directions.

McPherson, R. A., 2007: A review of vegetation-atmosphere interactions and their influences on mesoscale phenomena. Prog. Phys. Geogr., 31, 261-285, https://doi.org/10.1177/ 0309133307079055.

— environment: A technical update on the Oklahoma Mesonet. J. Atmos. Oceanic Technol., 24, 301-321, https://doi.org/ 10.1175/JTECH1976.1.

Miralles, D. G., W. T. Crow, and M. H. Cosh, 2010: Estimating spatial sampling errors in coarse-scale soil moisture estimates derived from point-scale observations. J. Hydrometeor., 11, 1423-1429, https://doi.org/10.1175/2010JHM1285.1.

Nateghi, R., S. D. Guikema, and S. M. Quiring, 2014: Forecasting hurricane-induced power outage durations. Nat. Hazards, 74, 1795-1811, https://doi.org/10.1007/s11069-014-1270-9.

Ochsner, T. E., and Coauthors, 2013: State of the art in large-scale soil moisture monitoring. Soil Sci. Soc. Amer. J., 77, 18881919, https://doi.org/10.2136/sssaj2013.03.0093.

Orth, R., and S. I. Seneviratne, 2014: Using soil moisture forecasts for sub-seasonal summer temperature predictions in Europe. Climate Dyn., 43, 3403-3418, https://doi.org/10.1007/s00382014-2112-x.

Otkin, J., M. Svoboda, E. D. Hunt, T. W. Ford, M. C. Anderson, C. Hain, and J. B. Basara, 2018: Flash droughts: A review and assessment of the challenges imposed by rapid-onset droughts in the United States. Bull. Amer. Meteor. Soc., 99, 911-919, https://doi.org/10.1175/BAMS-D-17-0149.1.

Pan, W., R. P. Boyles, J. G. White, and J. L. Heitman, 2012: Characterizing soil physical properties for soil moisture monitoring in the North Carolina Environment and Climate Observing Network. J. Atmos. Oceanic Technol., 29, 933-943, https://doi.org/10.1175/JTECH-D-11-00104.1.

Patrignani, A., and T. E. Ochsner, 2018: Modeling transient soil moisture dichotomies in landscapes with intermixed land covers. J. Hydrol., 566, 783-794, https://doi.org/10.1016/ j.jhydrol.2018.09.049.

— C. B. Godsey, T. E. Ochsner, and J. T. Edwards, 2012: Soil water dynamics of conventional and no-till wheat in the Southern Great Plains. Soil Sci. Soc. Amer. J., 76, 1768-1775, https://doi.org/10.2136/sssaj2012.0082.

Phillips, A. J., N. K. Newlands, S. H. Liang, and B. H. Ellert, 2014: Integrated sensing of soil moisture at the field-scale: Measuring, modeling and sharing for improved agricultural decision support. Comp. Elec. Ag., 107, 73-88, https://doi.org/ 10.1016/j.compag.2014.02.011.

Quinn, N. W., R. Ortega, P. J. Rahilly, and C. W. Royer, 2010: Use of environmental sensors and sensor networks to develop water and salinity budgets for seasonal and wetland real-time water quality management. Environ. Modell. Software, 25, 1045-1058, https://doi.org/10.1016/j.envsoft.2009.10.011.

Quiring, S. M., and T. N. Papakryiakou, 2003: An evaluation of agricultural drought indices for the Canadian prairies. Agric. For. Meteor., 118, 49-62, https://doi.org/10.1016/S01681923(03)00072-8.

_, L. Zhu, and S. D. Guikema, 2011: Importance of soil and elevation characteristics for modeling hurricane-induced power outages. Nat. Hazards, 58, 365-390, https://doi.org/10.1007/ s11069-010-9672-9. 
Robinson, D. A., 2005: The New Jersey Weather and Climate Network: Providing environmental information for a myriad of applications. 15th Conf. on Applied Climatology, Savannah, GA, Amer. Meteor. Soc., J2.1, https://ams.confex.com/ams/ 15AppClimate/webprogram/Paper94206.html.

Sanchez, N., J. Martinez-Fernández, A. Scaini, and C. PerezGutierrez, 2012: Validation of the SMOS L2 soil moisture data in the REMEDHUS network (Spain). IEEE Trans. Geosci. Remote Sens., 50, 1602-1611, https://doi.org/10.1109/ TGRS.2012.2186971.

Sandborn, A., and Coauthors, 2019: NASS geospatial applications from the cropland data layer. ISI World Statistics Conf., Kuala Lumpur, Malaysia, International Statistical Institute, 6 pp., https://www.nass.usda.gov/Research_and_Science/Cropland/ docs/ISI\%20WSC\%20Paper\%20-\%20Sandborn.pdf.

Santanello, J. A., Jr., C. D. Peters-Lidard, and S. V. Kumar, 2011: Diagnosing the sensitivity of local land-atmosphere coupling via the soil moisture-boundary layer interaction. J. Hydrometeor., 12, 766-786, https://doi.org/10.1175/JHM-D-10-05014.1.

Schaefer, G. L., and R. F. Paetzold, 2001: SNOTEL (SNOwpack TELemetry) and SCAN (Soil Climate Analysis Network). Automated Weather Stations for Applications in Agriculture and Water Resources Management: Current Perspectives. K. G. Hubbard and M. V. K. Sivakuman, Eds., WMO/TD 1074, 187-194, http://www.wamis.org/agm/pubs/agm3/WMO-TD1074.pdf.

—, M. H. Cosh, and T. J. Jackson, 2007: The USDA natural resources conservation service Soil Climate Analysis Network (SCAN). J. Atmos. Oceanic Technol., 24, 2073-2077, https:// doi.org/10.1175/2007JTECHA930.1.

Schroeder, J. L., W. S. Burgett, K. B. Haynie, and I. Sonmez, 2005: The West Texas Mesonet: A technical overview. J. Atmos. Oceanic Technol., 22, 211-222, https://doi.org/10.1175/ JTECH-1690.1.

Scipal, K. M., M. Drusch, and W. Wagner, 2008: Assimilation of a ERS scatterometer derived soil moisture index in the ECMWF numerical weather prediction system. Adv. Water Resour., 31, 1101-1112, https://doi.org/10.1016/j.advwatres.2008.04.013.

Scott, B. L., T. E. Ochsner, B. G. Illston, C. A. Fiebrich, J. B. Basara, and A. J. Sutherland, 2013: New soil property database improves Oklahoma Mesonet soil moisture estimates. J. Atmos. Oceanic Technol., 30, 2585-2595, https://doi.org/ 10.1175/JTECH-D-13-00084.1.

Sehgal, V., V. Sridhar, and A. Tyagi, 2017: Stratified drought analysis using a stochastic ensemble of simulated and in-situ soil moisture observations. J. Hydrol., 545, 226-250, https:// doi.org/10.1016/j.jhydrol.2016.12.033.

Seneviratne, S. I., T. Corti, E. L. Davin, M. Hirschi, E. B. Jaeger, I. Lehner, B. Orlowsky, and A. J. Teuling, 2010: Investigating soil moisture-climate interactions in a change climate: A review. Earth-Sci. Rev., 99, 125-161, https://doi.org/10.1016/ j.earscirev.2010.02.004.
Sheffield, J., and Coauthors, 2014: A drought monitoring and forecasting system for sub-Sahara African water resources and food security. Bull. Amer. Meteor. Soc., 95, 861-882, https:// doi.org/10.1175/BAMS-D-12-00124.1.

Silvestro, F., and N. Rebora, 2014: Impact of precipitation forecast uncertainties and initial soil moisture conditions on a probabilistic flood forecasting chain. J. Hydrol., 519, 1052-1067, https://doi.org/10.1016/j.jhydrol.2014.07.042.

Soulis, K. X., S. Elmaloglou, and N. Dercas, 2015: Investigating the effects of soil moisture sensors positioning and accuracy on soil moisture based drip irrigation scheduling systems. Agric. Water Manage., 148, 258-268, https://doi.org/10.1016/ j.agwat.2014.10.015.

South Dakota State University, 2020: South Dakota Mesonet Database. Accessed 5 January 2020, https://climate.sdstate.edu/archive/.

State Climate Office of North Carolina, 2020: CRONOS. North Carolina State University, accessed 5 January 2020, https:// climate.ncsu.edu/cronos.

University at Albany, 2020: New York Mesonet. Accessed 5 January 2020, http://www.nysmesonet.org/.

Wanders, N., M. F. Bierkens, S. M. de Jong, A. de Roo, and D. Karssenberg, 2014: The benefits of using remotely sensed soil moisture in parameter identification of large-scale hydrological models. Water Resour. Res., 50, 6874-6891, https:// doi.org/10.1002/2013WR014639.

Wood, A. W., 2008: The University of Washington Surface Water Monitor: An experimental platform for national hydrologic assessment and prediction. 22nd Conf. on Hydrology, New Orleans, LA, Amer. Meteor. Soc., 5.2, https://ams.confex.com/ ams/88Annual/techprogram/paper_134844.htm.

Xia, Y., and Coauthors, 2012: Continental-scale water and energy flux analysis and validation for the North American Land Data Assimilation System project phase 2 (NLDAS-2): 1. Intercomparison and application of model products. J. Geophys. Res., 117, D03110, https://doi.org/10.1029/2011JD016051.

_ J. Sheffield, M. B. Ek, J. Dong, N. Chaney, H. Wei, J. Meng, and E. F. Wood, 2014: Evaluation of multi-model simulated soil moisture in NLDAS-2. J. Hydrol., 512, 107-125, https:// doi.org/10.1016/j.jhydrol.2014.02.027.

—, M. B. Ek, Y. Wu, T. W. Ford, and S. M. Quiring, 2015: Comparison of NLDAS-2 simulated and NASMD observed daily soil moisture. Part I: Comparison and analysis. J. Hydrometeor., 16, 1962-1980, https://doi.org/10.1175/JHM-D-14-0096.1.

Yilmaz, M. T., and W. T. Crow, 2013: The optimality of potential rescaling approaches in land data assimilation. J. Hydrometeor., 14, 650-660, https://doi.org/10.1175/JHM-D-12-052.1.

Zamora, R. J., F. M. Ralph, E. Clark, and T. Schneider, 2011: The NOAA Hydrometeorology Testbed soil moisture observing networks: Design, instrumentation, and preliminary results. J. Atmos. Oceanic Technol., 28, 1129-1140, https://doi.org/ 10.1175/2010JTECHA1465.1. 